\title{
Low-velocity impact behaviour of woven laminate plates with fire
}

\section{retardant resin}

\author{
Marzio Grasso ${ }^{1 *}$, Yigeng Xu ${ }^{2}$, Amit Ramji ${ }^{2}$, Gang Zhou ${ }^{3}$, Andreas Chrysanthou ${ }^{4}$, George Haritos ${ }^{1}$ and \\ Yong Chen ${ }^{4}$
}

1 Kingston University, School of Engineering and the Environment

2 Cranfield University, School of Aerospace, Transport and Manufacturing

3 Loughborough University, Aeronautical and Automotive Engineering

4 University of Hertfordshire, School of Engineering and Computer Science

* Correspondence: m.grasso@kingston.ac.uk

Abstract: The description of the damage mechanisms of woven laminate plates under low-velocity impact is challenging as the damage mechanisms at the interface of adjacent layers are dominated by the fibre architecture. This work presents an experimental investigation of the behaviour of woven glass and carbon fibre composite laminates with fire retardant resin under low-velocity impact. The performance are evaluated in terms of damage mechanisms and force time history curves. Six impact energy levels have been used to test standard plates and identify the type of damage observed at different energy levels. Scanning electron microscopy (SEM) along with C-scans have been used to characterise the damage. It has been observed that in woven composites, the damage is mostly between the fibre bundles and the matrix and as the impact energy increases the failure involves extended matrix cracking and fibre fracture. Moreover, due to the fibre architecture, both the contact forces between bundles of fibres and the stretching of the bundles are responsible for the dominant matrix cracking damage mode observed at the low-impact energy level. As the impact energy increases, the damage also increases resulting in fibre fracture at relatively high impact energy. The experimental evidence collected with this work shows that for both the carbon fibre and the glass 
fibre woven laminates the low-velocity impact behaviour is characterised by extended fibre fracture without noticeable sudden load drop.

Keywords: Low-velocity impact; woven composite; delamination; matrix crack, fibre breakage.

\section{Introduction}

Composite laminates are often subjected to low-velocity impact while in service and during manufacture $[1,2]$. Unlike their damage-tolerant metallic counterparts, which can absorb impact energy via plastic deformation, composite laminates tend to suffer internal damage due to the inherent brittle nature of the fibres and the matrix. This can lead to a further propagation during in service loading. Barely-visible impact damage (BVID) can be introduced at any point of the laminate [3], sometimes far away from the impact site. At low-velocity and low-energy impact [4], typical damage mechanisms include indentation, matrix cracking, delamination, fibre fracture and back-face fibre splitting $[5,6]$. The first stage of damage is usually matrix cracking, but this does not significantly alter the laminate stiffness [7]. However, the crack tips can act as initiation sites for delamination and fibre breakage during further loading scenarios. The residual strength of the composite panel after impact is also related to the extent of delamination. Attempts to map the impacted region and identify the type and extent of damage has been reported in the literature [8]. Under low-velocity and low-energy impact, four main damage regions, each of them characterised by a different type of damage, were reported [9]. The central region suffered mainly matrix cracking whilst the external areas were mainly affected by interface debonding and delamination [9].

Great attention has been devoted to the assessment of the effects of various parameters on lowvelocity impact damage. These parameters include; thickness $[10,11]$, fibre orientation, fibre crimp $[12,13]$, type of resin and type of fibre [14]. Several authors $[1,4,15,16]$ studied the effect of the ply thickness on the damage resistance and damage tolerance by analysing the results of impact tests and the compressive residual strength. In most cases it has been observed that thicker plies predominantly lead to delamination, while thinner plies experience fibre breakage during impact [16, 
17]. Referring to the various stages of damage, when the impact energy is very low, no damage is usually detected [18]. By increasing the impact energy, delamination is initially observed followed by fibre damage at higher energy levels. It has also been observed that the stiffness of the plates is mostly affected by the delamination [10]. For thin plates, the membrane effects become significant before fibre fracture happens producing mostly delamination rather than matrix cracks. For high energy impact, fibre damage is observed in the form of a "saw-tooth" pattern in the force history response [19]. Samples of greater thickness exhibit different behaviour with extended fibre fracture at high energy impact and a local decrease in stiffness in correspondence with the impact area, which results in perforation of the plate.

The interactions among the above mechanisms rely on several parameters such as materials variables, loading conditions, fibre configurations and stacking sequence. The improvement of the impact damage resistance has been a challenge in composite materials and most of the techniques developed are based on two main approaches; one involves the fibre architecture and the other the improvement of the material properties of the constituents. The fibre architecture approach is related to the way the fibres are arranged to produce $2 \mathrm{D}$ and $3 \mathrm{D}$ structures. The material property approach leads to the improvement of the fracture toughness of the matrix as well as the bonding between fibres and matrix. For that reason several studies have been carried out in order to improve the bonding between fibres and matrix by treating the fibre surface as well as developing tougher resins.

In the present study, the damage mechanisms induced by low-velocity impact are investigated through the analysis of cross-sections of damaged areas at different impact energy levels for two different fibre materials, namely glass fibres and carbon fibres. The damage morphology of the crosssections under various impact energy levels allows the observation of the different mechanisms involved in the impact damage and the way the damage evolves with energy. The main differences in the damage morphology between the unidirectional and the woven materials are highlighted.

\section{Materials and Methods}




\subsection{Materials and specimen compositions}

The experimental results have been collected by testing glass and carbon composite plates under lowvelocity impact. 36 specimens for each type of fibre were manufactured by layup of prepreg materials followed by curing in an autoclave. The carbon composite plates are composed of 11 laminae arranged in a layup sequence of $\left[(0 / 90)_{5} \overline{90}\right]_{s}$. The carbon fibre composite was made of E720/T300, which is a multiple prepreg manufactured by TenCate. TenCate E720 is a toughened epoxy resin system for cures at $120^{\circ} \mathrm{C}$ for 90 minutes, pre-impregnated into high-performance fibres such as carbon and glass. T300 is a woven carbon fibre ply, with a fabric density of 280 GSM, twilled in $2 \times 2$ weave style. The glass composite plates were composed of 11 Texipreg EE300/EF452 laminae arranged in a layup sequence of $\left[(0 / 90)_{\mathrm{F}}\right]_{11}$. EF452 is a fire retardant, self-adhesive prepreg system which contains no halogenated flame retardants. It is suitable for sandwich panels or solid laminates. EE300 is a plain weave glass fibre ply, with a fabric density of 300 GSM. The final range of thickness values for the carbon and glass composite plates is $4.6 \pm 0.06 \mathrm{~mm}$ and $3.42 \pm 0.02 \mathrm{~mm}$ respectively. The mechanical properties of the glass and carbon fibres are shown in Tables 1 and 2. Early research on woven composite laminates with flame retardant resins [26-28] has shown that the additive used to enhance the flame-retardancy of the resin lead to an improvement in the thermal properties and a reduction in the mechanical properties. Moreover, the additives have been observed to improve the impact strength and the Interlaminar Shear Strength (ILSS), this latter is responsible for the enhanced low velocity impact performance compared to the conventional woven composite laminates.

For each type of fibres, the plates were cut out from a single panel. Low-velocity impact tests were performed in accordance with ASTM D7136/D7136M Standard [20] using an Imatek drop-weight tower shown in Fig. 1. The total mass of the striker was $2.464 \mathrm{~kg}$ and the impactor diameter was 25 $\mathrm{mm}$. Prior to the impact tests, a C-Scan was performed for all samples in order to assess the initial damage status. The damage produced after impact was assessed by using the same non-destructive method. 
Table 1. Mechanical Properties of Carbon fibre reinforced woven layer

\begin{tabular}{|c|c|c|c|c|}
\hline Property & Condition & Standard Method & Typical Value & Units \\
\hline Tensile Strength & RTD & EN ISO 524-4 & 621 & $\mathrm{MPa}$ \\
\hline Tensile Modulus & RTD & EN ISO 524-4 & 58.4 & $\mathrm{GPa}$ \\
\hline Compression Strength & RTD & EN 2850 & 488 & $\mathrm{MPa}$ \\
\hline Compression Modulus & RTD & EN 2850 & 70 & $\mathrm{GPa}$ \\
\hline In-Plane Shear Strength & RTD & EN ISO 14129 & 99 & $\mathrm{MPa}$ \\
\hline In-Plane Shear Modulus & RTD & EN ISO 14129 & 3.5 & $\mathrm{GPa}$ \\
\hline Flexural Strength & RTD & EN ISO 14125 & 801 & $\mathrm{MPa}$ \\
\hline Flexural Modulus & RTD & EN ISO 14125 & 52.4 & $\mathrm{GPa}$ \\
\hline ILSS & RTD & EN ISO 14130 & 62.1 & $\mathrm{MPa}$ \\
\hline
\end{tabular}

https://www.tencatecomposites.com/product-explorer/products/aBwR/E720

Table 2. Mechanical Properties of Glass fibre reinforced woven layer.

\begin{tabular}{|c|c|c|c|c|}
\hline Cured Material Properties (1) & Condition & Standard Method & Typical Value & Unit \\
\hline Cured Ply Thickness & RTD & & 0.22 & $\mathrm{~mm}$ \\
\hline Tensile Strength & RTD & ASTM D 3039 & 450 & $\mathrm{MPa}$ \\
\hline Tensile Modulus & RTD & ASTM D 3039 & 24.5 & $\mathrm{GPa}$ \\
\hline Flexural Strength & RTD & ASTM D 790 & 480 & $\mathrm{MPa}$ \\
\hline Flexural Modulus & RTD & ASTM D 790 & 24 & GPa \\
\hline Compressive Strength & RTD & $\begin{array}{l}\text { Modified ASTM D695 } \\
\text { (SACMA SRM 1-88) }\end{array}$ & N/A & $\mathrm{MPa}$ \\
\hline ILSS & RTD & ASTM D 2344 & 35 & $\mathrm{MPa}$ \\
\hline
\end{tabular}

http://www.saati.de/images/composites/prepregs/ef452.pdf

(1) The tests were carried out @ $23^{\circ} \mathrm{C}$ and 60\% R.H. on specimens cured in std conditions (dwell @150 for 1 hour in hot plate press. External pressure applied: 3 bar). The 


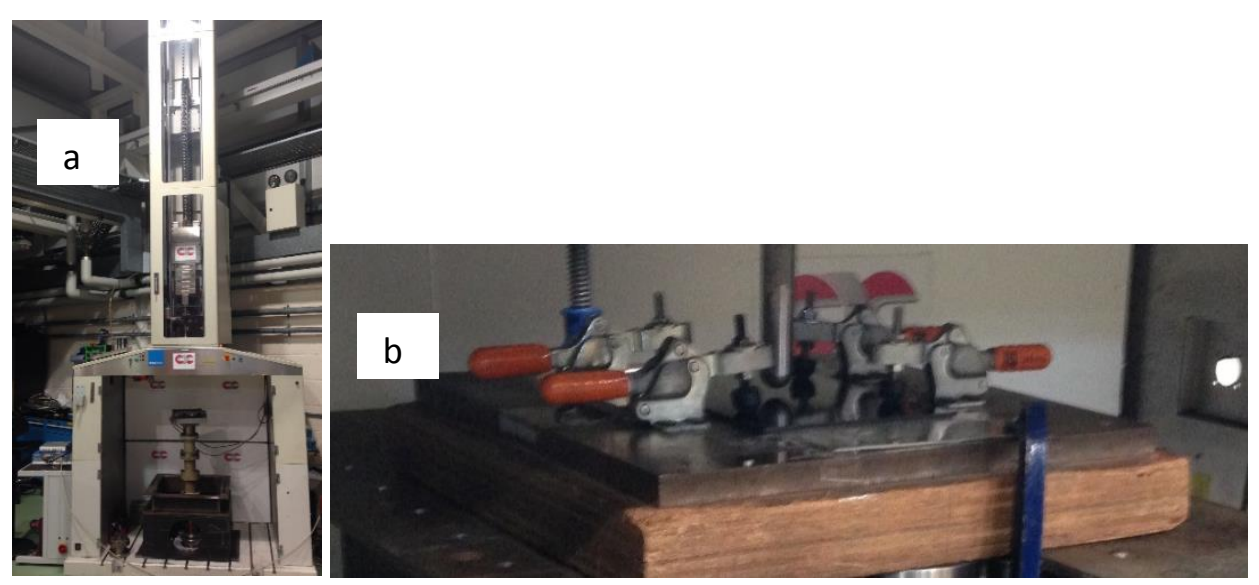

Fig. 1. Drop-weight tower used for the low velocity impact testing: a) the drop weight machine, b) the holding mechanism for the sample in the drop tower.

The impact energy is controlled by the drop height to provide the nominal impact energy values of 5J, 7.5J, 10J, 15J, 20J, and 30J. The specimens were clamped on a rectangular plate as shown in Fig. $1 \mathrm{~b}$. Time histories of the impact force, velocity, acceleration, and displacement were obtained. The load cell used was a calibrated Kistler 9331B in-line load cell connected by a gold plated coaxial cable attached to a Kistler analyser and Imatek C3008 signal amplifier.

Ultrasound scanning techniques using a Sonatest Veo 16:64 with a $45^{\circ}$ probe in a water tank were used for the detailed identification of the post-impact damage area. Finally, some of the specimens were cut carefully into two halves along a central line to reveal the damage inside and was examined by Scanning Electron Microscopy (SEM) using a JEOL JEM-1400 Plus.

\section{Results and discussion}

\subsection{Dynamic response of woven composite plates under low velocity impact}

Fig.2 shows the impact force-time histories of the woven composite laminate plates under the lowvelocity impact at six energy levels. 


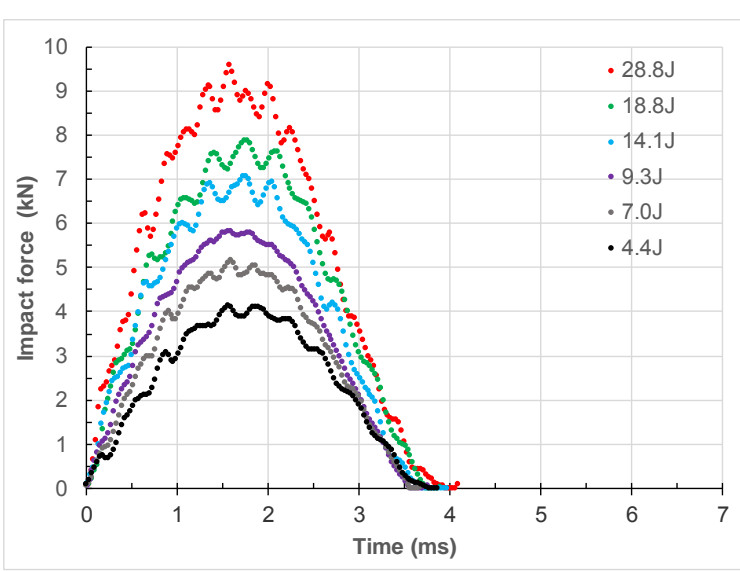

(a)

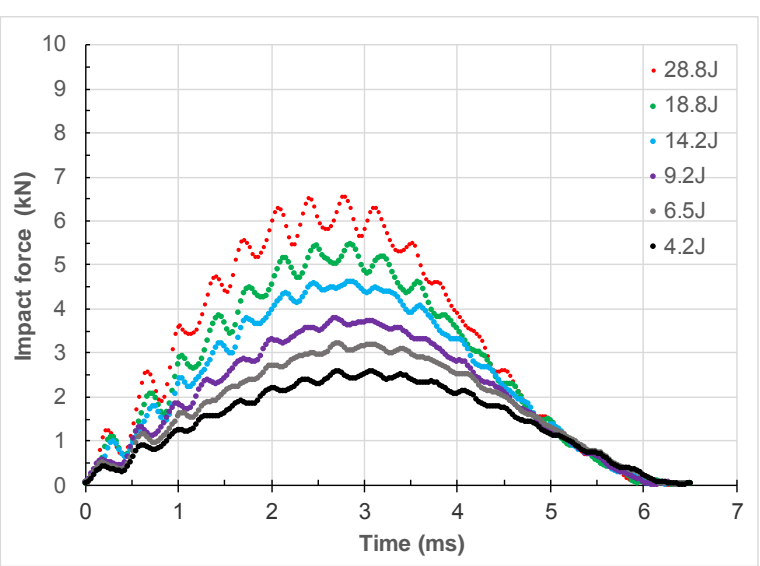

(b)

Fig. 2 Impact force - time curves of (a) woven carbon fibre composite laminates and (b) woven glass fibre composite laminates

The general trend of the dynamic response is similar for the two woven plates made of different reinforcement fibres. The impact duration is independent of the impact energy level. The profile of the impact force history is symmetrical [21] about the peak impact force and can be described by a sine function. This is in contrast to what observed with unidirectional composite laminates where the force-time curve is shifted towards the loading phase when impact damage is introduced [15]. The fluctuations of the impact force about the sine wave profile are primarily due to elastic wave responses and vibration of the specimen and are repeatable for replicate tests [15]. At low-impact energy, indentation illustrated in Fig.3 is the main damage mechanism and the level of the force fluctuation on the loading phase is similar to that on the unloading phase. At high-impact energy when other damage mechanisms are activated, the force fluctuation on the loading phase becomes bigger while the unloading phase is much smoother.
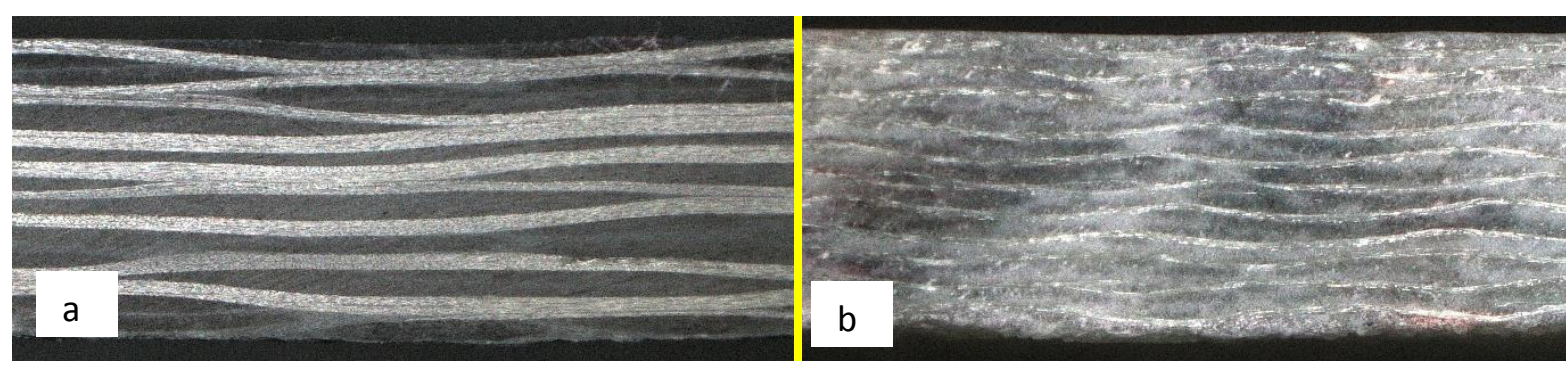

Fig. 3 Cross section to show the indentation of a) carbon fibre sample tested at $10 \mathrm{~J}$ and b) glass fibre sample tested at $5 \mathrm{~J}$. 
Table 3. Experimental results obtained for the Carbon Fibre Composite tested at Low Velocity Impact.

\begin{tabular}{|ccccc|} 
Impact Energy $(\mathrm{J})$ & Absorbed Energy $(\mathrm{J})$ & $\begin{array}{c}\text { Peak } \\
\text { Force }(\mathbf{N})\end{array}$ & $\begin{array}{c}\text { Maximum } \\
\text { Displacement (mm) }\end{array}$ & $\begin{array}{c}\text { Impact Duration } \\
\text { (ms) }\end{array}$ \\
\hline 4.49 & 0.557 & 4206 & 2.06 & 3.90 \\
\hline 6.99 & 1.595 & 5077 & 2.55 & 3.66 \\
\hline 9.27 & 2.179 & 5764 & 2.84 & 3.63 \\
\hline 14.11 & 3.925 & 7051 & 3.53 & 3.69 \\
\hline 18.83 & 6.489 & 8149 & 4.17 & 3.72 \\
\hline 28.80 & 13.120 & 9516 & 5.41 & 3.81 \\
\hline
\end{tabular}

Table 4. Experimental results obtained for the Glass Fibre Composite tested at Low Velocity Impact

\begin{tabular}{|ccccc|}
\hline Impact Energy (J) & Absorbed Energy (J) & $\begin{array}{c}\text { Peak } \\
\text { Force (N) }\end{array}$ & $\begin{array}{c}\text { Maximum } \\
\text { Displacement (mm) }\end{array}$ & $\begin{array}{c}\text { Impact Duration } \\
(\mathbf{m s})\end{array}$ \\
\hline 4.24 & 0.202 & 2563 & 2.87 & 6.33 \\
\hline 6.70 & 0.714 & 3158 & 4.16 & 6.18 \\
\hline 9.20 & 1.912 & 3740 & 4.94 & 6.18 \\
\hline 14.06 & 4.706 & 4776 & 5.77 & 6.09 \\
\hline 19.09 & 7.389 & 5500 & 6.91 & 6.15 \\
\hline 28.39 & 14.190 & 6469 & 8.39 & 6.24 \\
\hline
\end{tabular}

The woven carbon fibre laminate plate exhibit overall a $40 \%$ shorter impact duration and a minimum of $47 \%$ greater peak value of the maximum force compared with the woven glass fibre laminate plates under similar impact energy levels. This different behaviour is related to the lower stiffness of the glass fibre composite compared to the carbon fibre composite. The difference in stiffness is also responsible for the higher deflection of the glass fibre composite plate (37\% on average) under the maximum force compared to the carbon fibre composite plate. The maximum vertical displacement measured during the low velocity impact tests has been compared with the maximum deflection predicted with the plate theory using only the first four terms of the series. In particular, using the Navier solution [21] for the case of a simply-supported square plate with a single load concentrated at the central point, the maximum deflection can be expressed as

$w_{\max }=\frac{0.01121 P a^{2}}{D}$

Where $\mathrm{P}$ is the single load applied in the middle of the plate, $a$ is the side length of the plate and $\mathrm{D}$ is the flexural rigidity of the plate defined as 
$D=\frac{E h^{3}}{12\left(1-v^{2}\right)}$

Where $\mathrm{E}$ is the equivalent elastic modulus, $v$ is the Poisson's ratio and $\mathrm{h}$ is the thickness of the plate. Using Eq. (1) and the maximum load values reported in Table 3 and Table 4 the maximum deflection was derived and compared with the experimental values. Fig. 4 shows the good agreement of the maximum deflection values between the experimental results and the theoretical predictions with Eq. (1).

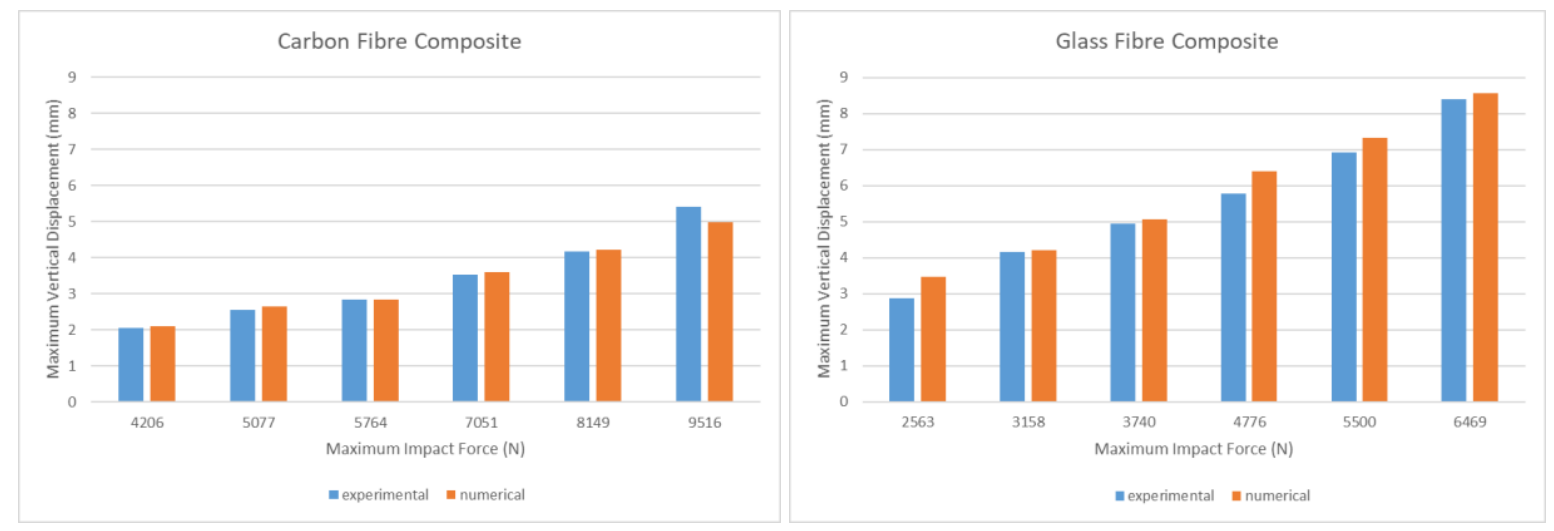

Fig. 4 Comparison of the experimental and theoretical maximum deflection of a) carbon fibre samples and b) glass fibre samples.

The force-time history curves in Fig.2 show no noticeable sudden load drop for the woven plates with both fibre types. This observation is different from that for unidirectional composite laminates where a sudden load drop is commonly used to identify the delamination threshold load due to specimen stiffness loss as a result of laminate level damage. The results of the present study are consistent with the observation of Giannopoulos et al [23] who were not able to identify a delamination threshold load from the filtered impact force time history curve of a woven composite plate. The low-velocity impact tests performed on woven composites by Kim and Sham [9] also showed no load drop nor slope changes until the load reached a maximum.

Fig. 5 shows the impact force-displacement histories of the woven composite laminate plates under low-velocity impact of the six energy levels. The load drop or change of slope of the loaddisplacement curve may indicate nominal stiffness reduction due to the introduction of damage [8, 24, 25]. It is however, worth noting that for both the woven carbon fibre laminate plate and the glass 
fibre laminate, there is no noticeable load drop of the loading phase even at the highest impact energy of 28.8J. However, the load displacement curves for the carbon composite show a change in the slope around $6.5 \mathrm{kN}$ (Fig. 5a). As shown by the SEM analysis discussed in the next paragraphs performed on the samples tested at higher energy, the change in slope could be linked to fibre fracture and delamination.
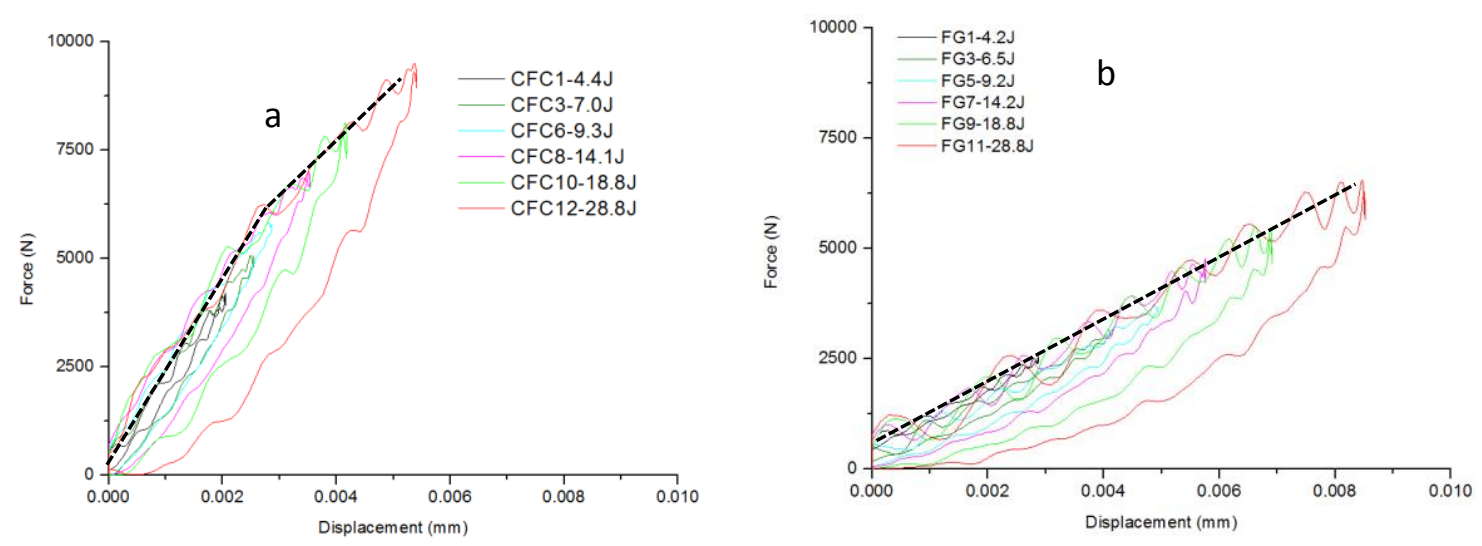

Fig. 5 Impact force - displacement curves of a) woven carbon fibre composite laminates and b) woven glass fibre composite laminates. Dotted lines show the change in stiffness observed for the carbon fibre composite.

There is no hysteresis in the loading and unloading phases for the woven carbon fibre plate under 4.4J impact and the woven glass fibre plate under 4.2J impact, indicating that there is no noticeable energy absorption through damage during the impact event. As the impact energy level increased, the unloading curve became well-separated from the loading curve indicating that the specimen absorbed a significant fraction of the impact energy level through local indentation and other damage mechanisms. The slope of the loading phase under high-impact energy levels, however, remains the same as the one under low-impact energy levels.

\subsection{Energy absorbed through damage mechanisms}

Fig. 6 shows the C-scan images with the damage areas of the woven plates under the six impact energy levels. The overall shape of the damage is elliptical. The impact damage is very small at low impact energy levels and may only be related to the local indentation. This is supported by the small hysteresis of the force-displacement curves shown in Fig. 5. The damage area shown in Fig. 6 
increases with the impact energy. The damage area for the glass fibre laminate plate increases more quickly than that of the woven carbon fibre plate.

a)

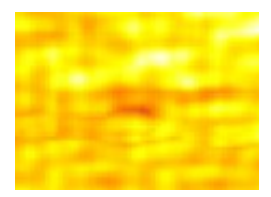

Damage area $=31 \mathrm{~mm}^{2}$

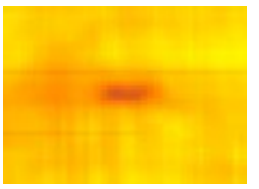

Damage area $=19 \mathrm{~mm}^{2}$

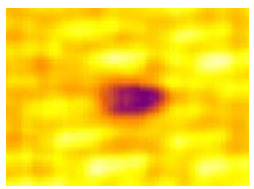

Damage area $=30 \mathrm{~mm}^{2}$

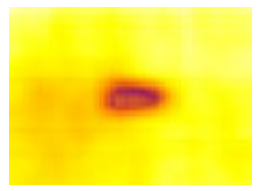

Damage area $=53 \mathrm{~mm}^{2}$

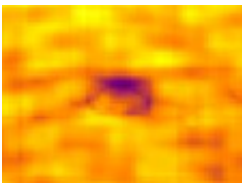

Damage area $=47 \mathrm{~mm}^{2}$

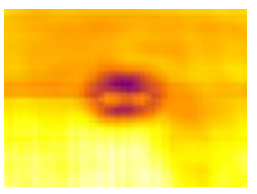

Damage area $=100 \mathrm{~mm}^{2}$
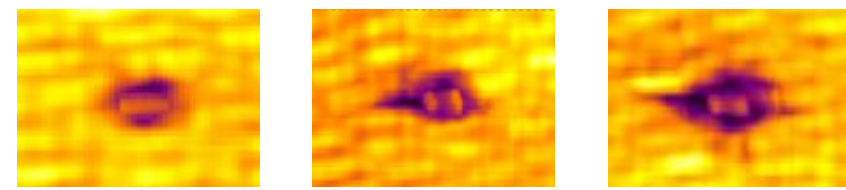

Damage area $=78 \mathrm{~mm}^{2}$

Damage area $=196 \mathrm{~mm}^{2}$

Damage area $=321 \mathrm{~mm}^{2}$

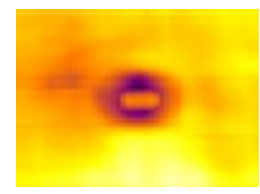

Damage area $=111 \mathrm{~mm}^{2}$

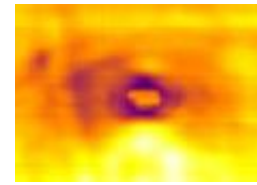

Damage area $=464 \mathrm{~mm}^{2}$

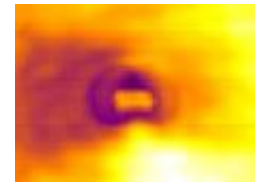

Damage area $=595 \mathrm{~mm}^{2}$

Fig. 6 C-scan images showing impact damage areas of a) the woven carbon fibre plates and b) the woven glass fibre plates under energy levels from low (left) to high (right).

Fig. 7 shows the energy-time histories of the woven composite laminate plates under low-velocity impact of the six energy levels. The energy absorbed by the composite laminates is represented by the difference between the initial impact energy and the kinetic energy of the impactor. The resulting plateau in the energy-time curve represents the energy absorbed by the composite laminates, primarily dissipated through the creation of damages.

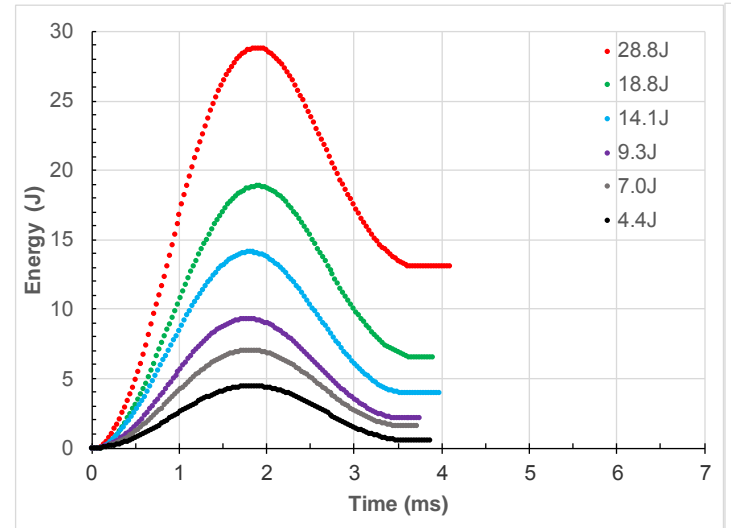

(a)

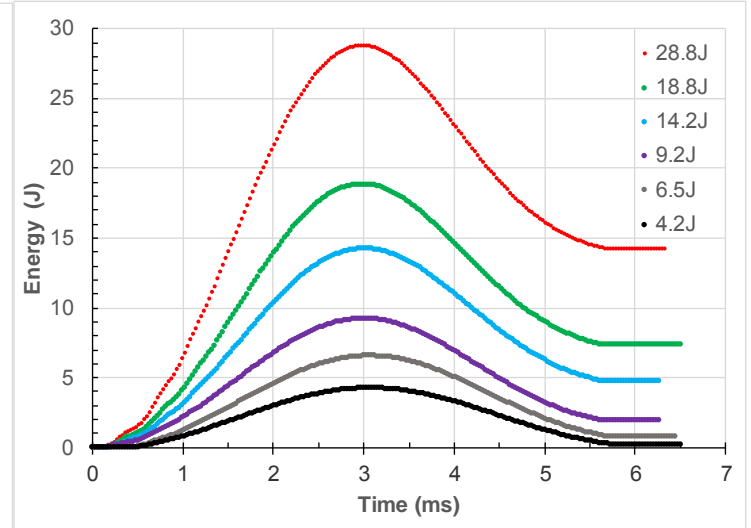

(b)

Fig. 7 Energy - time curves of (a) woven carbon fibre composite laminates and (b) woven glass fibre composite laminates 
Fig. 8 presents the energy absorbed through damage shown in Fig. 7 as a percentage of the impact energy. The results are consistent with those shown in Fig. 7 and show that at lower level of impact energy, the carbon fibre woven plate absorbs more energy than the glass fibre woven plate. At high level of impact energy (>9J), the glass fibre woven plate absorbs more energy than the carbon fibre woven plate, indicating a possible change of the damage mechanism in the two woven plates as the impact energy increases.

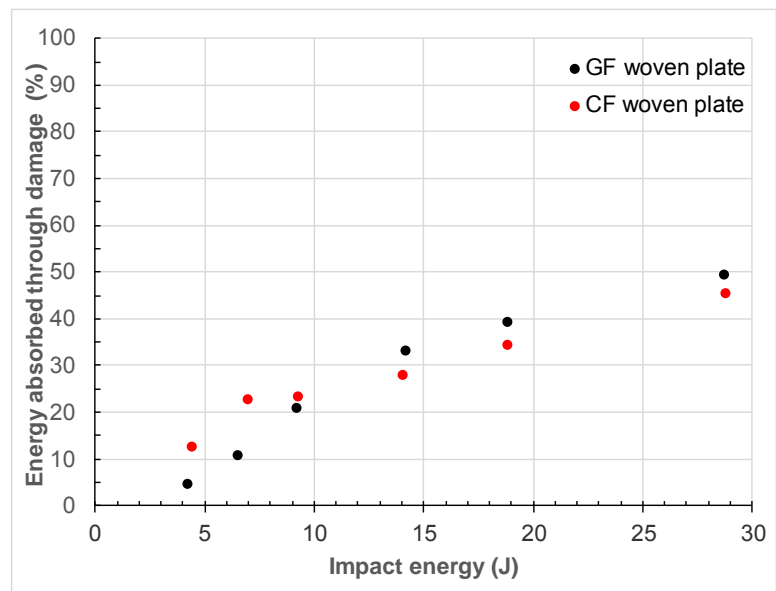

Fig. 8 Energy absorbed through damages as a percentage of the impact energy.

The symmetrical nature of the force-time history, the lack of sudden load drop, and the slope change of the force-time and force-displacement curves are observed consistently for the tests on the two types of woven laminate plates under the six different impact energy levels.

Early research on composite with flame retardant resins [26-28] has shown that the additive used to enhance the flame-retardancy of the resin lead to an improvement in the thermal properties and a reduction in the mechanical properties. Moreover, the additives have been observed to improve the impact strength and the Interlaminar Shear Strength (ILSS), this latter is responsible for the enhanced low velocity impact performance compared to the conventional woven composite laminates.

These observations are different to what have been commonly observed for unidirectional laminate plates under low velocity impact, indicating different damage mechanisms in woven plates. Matrix cracking may play a much more important role in energy absorption for woven laminate plates compared with unidirectional laminate plates where delamination is the dominant damage 
mechanism. Detailed microscopic examination of the sectioned samples carried out for the assessment of the damage mechanisms in woven laminate plates is presented and discussed in the following.

\section{Damage morphology of sectioned samples}

For the particular composite investigated in this work, it seems that the combination of strength of fibre-matrix bond and the inter-laminar fracture toughness $\left(G_{\| c}\right)$ are responsible for the feature of the force-time history curve in which a load drop is not evident. In order to describe the damage produced at different energy levels mainly in the three layers close to the bottom face, SEM (Scanning Electron Microscopy) examination was performed for cross-sections of the tested samples under all six impact energy levels. For very low-impact energy on carbon fibre composite the first level at which the damage is observed is $15 \mathrm{~J}$. For glass fibre composite the first damage is observed at $7 \mathrm{~J}$.

\subsection{Woven carbon fibre composites}

In Fig. 9, cross-sections of the carbon composite samples tested at 15J, 20J and 30J are shown. Matrix cracking is the first damage mechanism to be observed (Fig. 9 a) and it is associated with the damage at the interface between the fibres and the matrix from where the crack seems to initiate. The matrix cracking observed at 15J is also observed at 20J (Fig. 9 b) along with more extended damage at the interface and in-between the layers as the impact energy increases to 20J (Fig. 9 c). However, at higher-impact energy there is a higher deflection and most of the damage is located at the back-side of the plates. The higher deflection causes the back-side to be subjected to higher membrane strain resulting in fibre fracture and damage between adjacent layers (Fig. 9 d). 

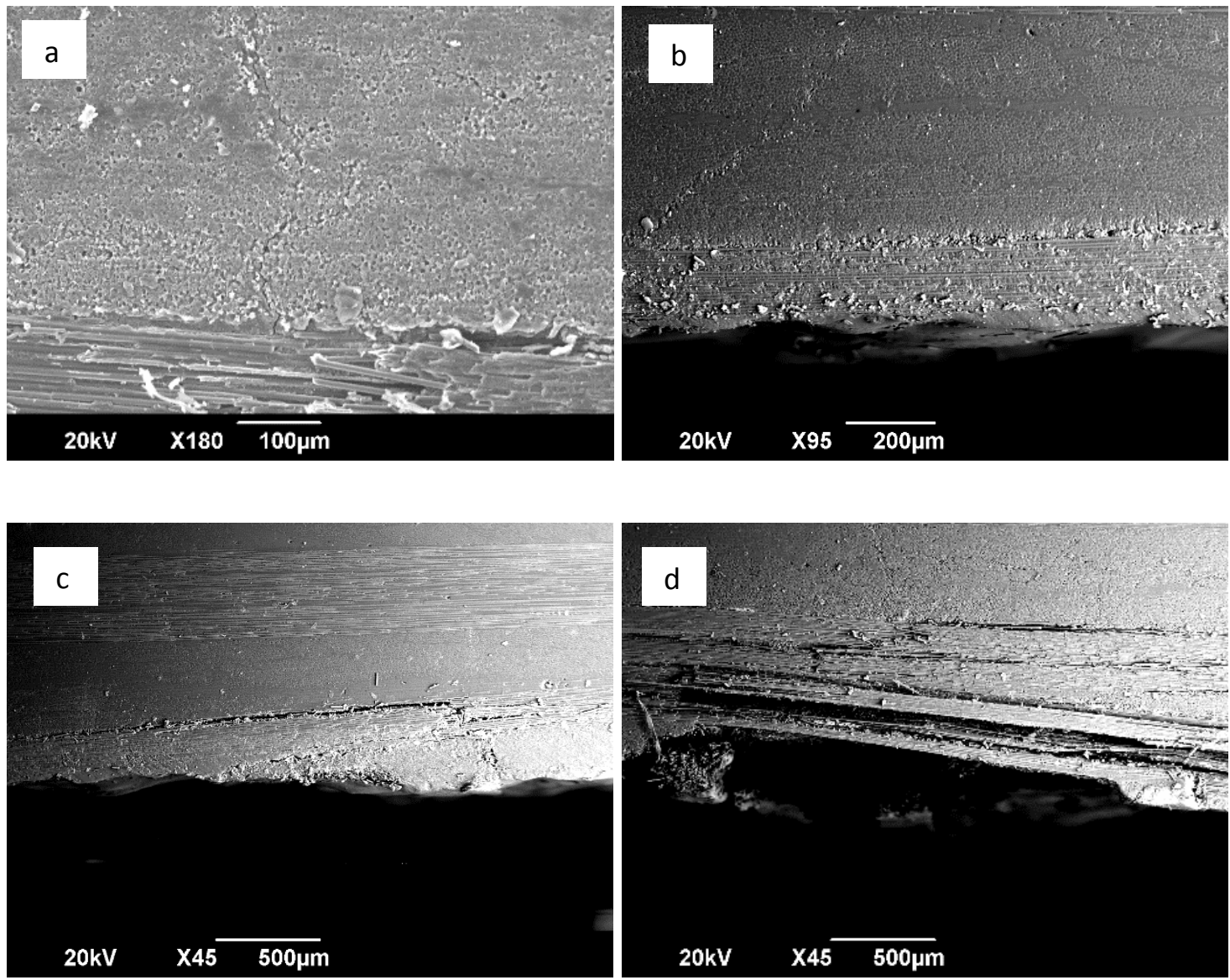

Fig. 9. SEM of the cross section of carbon composite plate tested at a) 15J, b) - c) 20J and d) 30J.

\subsection{Woven glass fibre composites}

SEM performed on the glass fibre composites shows that the damage appears at a lower impact energy compared to the carbon fibre composites (Fig. 10 a). In particular it is possible to identify three distinct levels in the sequence of the damage mechanisms. The first level only involves matrix cracking, the second level is a combination of matrix cracking and fibre fracture and the third level is characterised by extended damage on the back-side. 


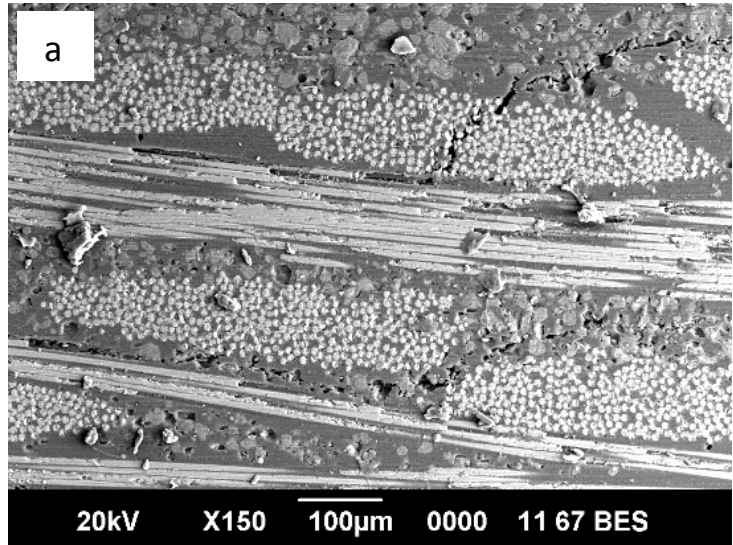

$20 \mathrm{kV}$

\section{$\mathrm{X} 150 \quad 100 \mu \mathrm{m} \quad 0000 \quad 1167 \mathrm{BES}$}

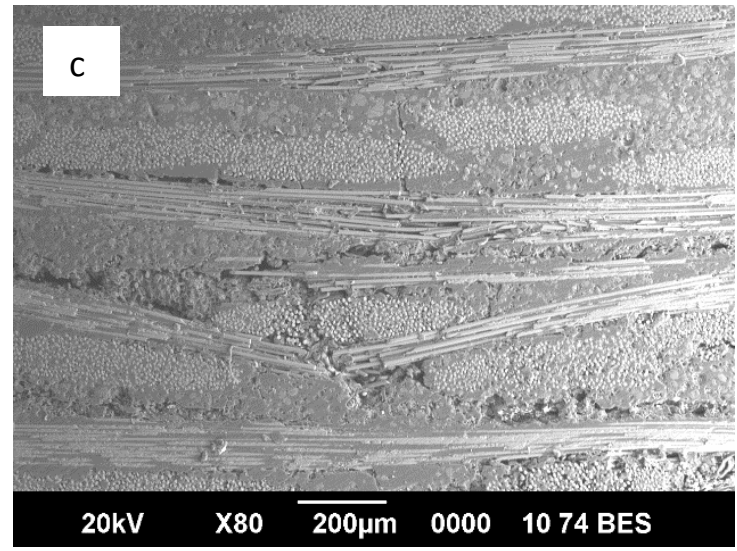

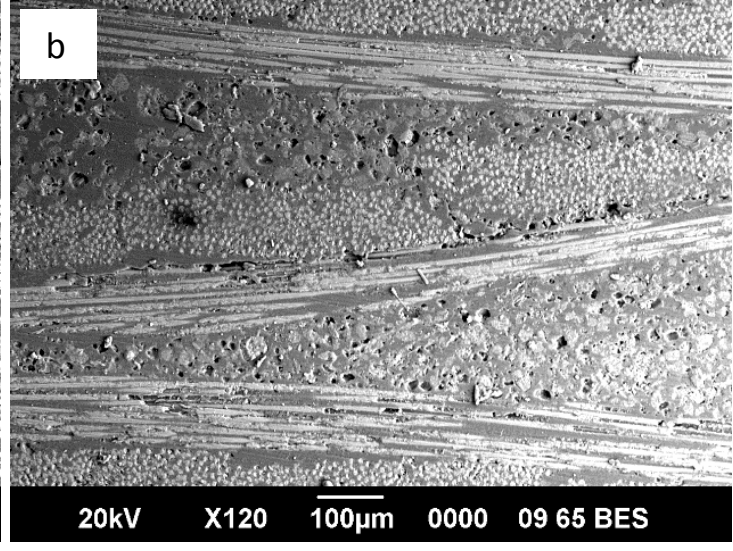

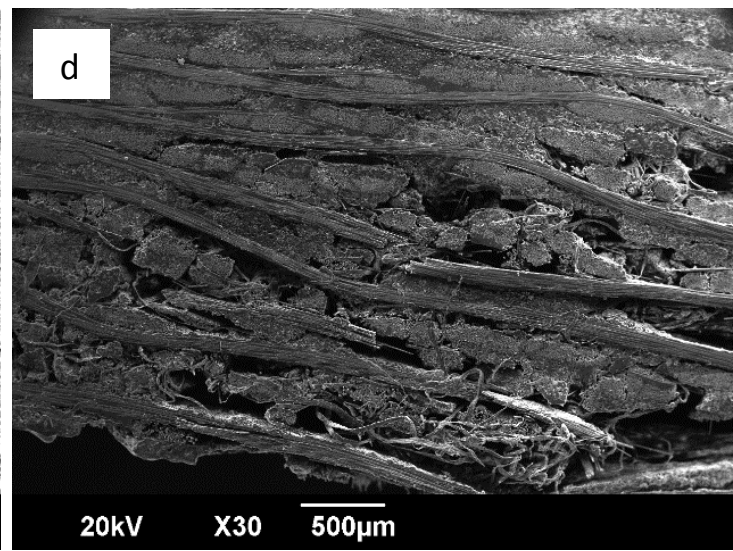

Fig. 10. SEM of the cross section of glass composite plate tested at a) 7J, b) 10J c) 15J and d) $30 \mathrm{~J}$.

The damage started at the interface between the fibres and the matrix (Fig. 10 a) and it propagated within the matrix following the fibres (Fig. 10 b) and the fibre bundles. The membrane stress acting in each layer stretched the fibre bundles pushing the bundles against the other producing a closure effect. For this reason the cracks produced in the matrix did not propagate between the bundles. At the higher-impact energy level the tension in the fibre bundles will act with a localised load on the bundle in contact (Fig 11) due to the waviness and the membrane stress associated with the higher deflection. Moreover, the higher deflection produces more strain in the fibres which acting with the localised load results in higher contact force at the interface between fibre bundles (Fig. $10 \mathrm{c}$ ) which in turns will promote fibre fracture. 


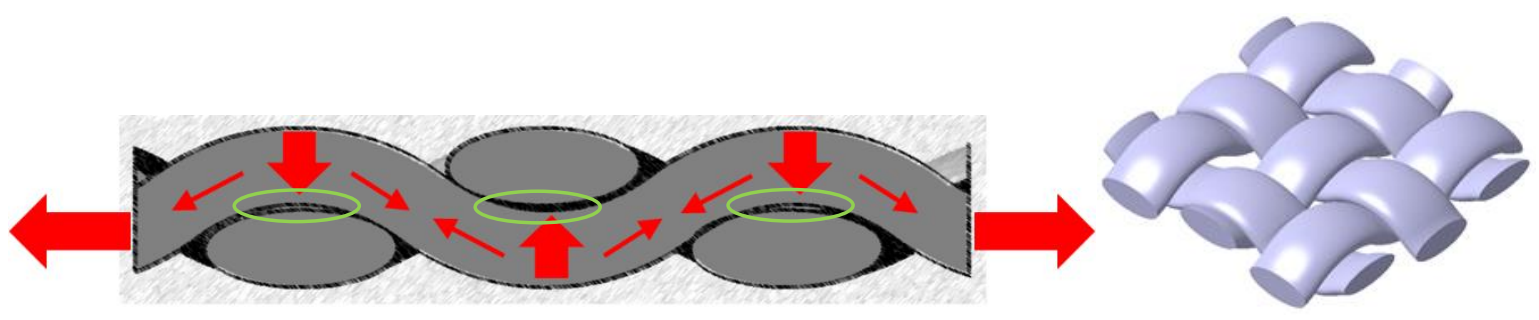

Fig. 11. Schematic representation of the forces in the bundles due to the bending.

The fibre damage together with the shear strain at the interface between fibres and the matrix promotes the propagation of matrix cracks and leads to more damage at the fibre-matrix interface. At the highest impact energy level considered in this work (30J), an extended damage at the back-side is observed (Fig. 10 d). The fibre fracture in several layers from the bottom face together with matrix damage has been observed.

The change in the slope is observed in the force-displacement curves for the carbon fibre and it is not observed for the glass fibre composite. The analysis of the damage mechanisms observed at different energy levels provides a possible justification for the above observation. The damage causing the change in stiffness in the carbon fibre composite is fibre fracture at the bottom face which is observed at high impact energy. In the glass fibre composite, fibre fracture appears at lower impact energy $(<7.5 \mathrm{~J})$ compared to the carbon composite. The change in the stiffness is affecting all the glass fibre composite plates and it is promoted by the stretching of the fibres due to the deflection of the plate. The deflection of the plates is responsible for the failure of the crossing fibre bundles at the contact areas (Fig. 11).

\section{Conclusions}

This work investigates the damage mechanisms observed in the woven composite laminate with fire retardant resin comparing carbon and glass fibre composites. The low velocity impact testing included 6 energy levels from $5 \mathrm{~J}$ to 30J. The mechanical behaviour of the glass and carbon fibre composite plates was compared using force-time and force-displacement history curves as well as SEM analysis 
of the cross sections to identify the damage induced at different energy levels. The results gather in this work show that:

- the woven carbon fibre laminate plate exhibit overall a $40 \%$ shorter impact duration and a $47 \%$ greater peak value of the maximum force compared with the woven glass fibre laminate plates under similar impact energy levels.

- The lower stiffness of the glass is responsible for the $37 \%$ higher deflection observed in the glass fibre composite plates.

- The damage area observed with the C-Scan in the carbon fibre composite plates is lower that observed in the glass fibre composite plates.

- The flame retardant additives enhance the strength of the interlayer interfaces compared to the woven fibre composite without these additives, resulting in limited delamination at any of the energy level investigated in this work.

- The damage in the tested woven composite laminates is localised at the interface between fibre bundles and matrix and as the impact energy increases more fibre fracture and matrix cracking are observed.

- The low velocity impact damage grows progressively without causing any sudden change in the stiffness and in the shape of the force-time history curves, due to the architecture of the woven composites.

- The fibre architecture of the woven material together with the toughened resin allow the woven laminates investigated in this study to better tolerate the damage.

\section{References}

[1] Y. Xu, Z. Shen, W. Tiu, Y. Xu, Y. K. Chen, and G. Haritos, "Delamination threshold load of composite laminates under low-velocity impact," in Key Engineering Materials, 2013, pp. 521-524. 
[2] M. Grasso, F. Penta, G. P. Pucillo, F. Ricci, and V. Rosiello, "Low velocity impact response of composite panels for aeronautical applications," in Proceedings of the World Congress on Engineering, 2015.

[3] W. Cantwell and J. Morton, "The impact resistance of composite materials-a review," composites, vol. 22, pp. 347-362, 1991.

[4] G. Schoeppner and S. Abrate, "Delamination threshold loads for low velocity impact on composite laminates," Composites Part A: applied science and manufacturing, vol. 31, pp. 903-915, 2000.

[5] D. Delfosse and A. Poursartip, "Energy-based approach to impact damage in CFRP laminates," Composites Part A: Applied Science and Manufacturing, vol. 28, pp. 647-655, 1997.

[6] G. P. Zhao, C. D. Cho, and O. Y. Kwon, "Simulation and experimental investigation of impact damage in composite shell," in Key Engineering Materials, 2005, pp. 1339-1343.

[7] F. Yang and W. Cantwell, "Impact damage initiation in composite materials," composites science and technology, vol. 70, pp. 336-342, 2010.

[8] Y. Hirai, H. Hamada, and J.-K. Kim, "Impact response of woven glass-fabric composites-I.: Effect of fibre surface treatment," Composites Science and Technology, vol. 58, pp. 91-104, 1998.

[9] J.-K. Kim and M.-L. Sham, "Impact and delamination failure of woven-fabric composites," Composites Science and Technology, vol. 60, pp. 745-761, 2000.

[10] C. Evci, "Thickness-dependent energy dissipation characteristics of laminated composites subjected to low velocity impact," Composite Structures, vol. 133, pp. 508-521, 2015.

[11] G. Belingardi and R. Vadori, "Influence of the laminate thickness in low velocity impact behavior of composite material plate," Composite Structures, vol. 61, pp. 27-38, 2003. 
[12] J. Baucom and M. Zikry, "Low-velocity impact damage progression in woven E-glass composite systems," Composites Part A: Applied Science and Manufacturing, vol. 36, pp. 658-664, 2005.

[13] T. J. Kang and C. Kim, "Energy-absorption mechanisms in Kevlar multiaxial warp-knit fabric composites under impact loading," Composites Science and Technology, vol. 60, pp. 773-784, 2000.

[14] C. Evci and M. Gülgeç, "An experimental investigation on the impact response of composite materials," International Journal of Impact Engineering, vol. 43, pp. 40-51, 2012.

[15] S. Abrate, Impact on composite structures: Cambridge university press, 2005.

[16] C. Lopes, O. Seresta, Y. Coquet, Z. Gürdal, P. Camanho, and B. Thuis, "Low-velocity impact damage on dispersed stacking sequence laminates. Part I: Experiments," Composites Science and Technology, vol. 69, pp. 926-936, 2009.

[17] M. Aktaş, C. Atas, B. M. İçten, and R. Karakuzu, "An experimental investigation of the impact response of composite laminates," Composite Structures, vol. 87, pp. 307-313, 2009.

[18] M. P. Cavatorta and D. S. Paolino, "Damage variables in impact testing of composite laminates," Composite Materials Research Progress, p. 237, 2008.

[19] N. K. Naik, Y. C. Sekher, and S. Meduri, "Damage in woven-fabric composites subjected to low-velocity impact," Composites Science and Technology, vol. 60, pp. 731-744, 2000.

[20] A. Standard, "D7136: Standard test method for measuring the damage resistance of a fiberreinforced polymer matrix composite to a drop-weight impact event," ASTM International: West Conshohocken, 2005.

[21] L. Sutherland and C. G. Soares, "Impact on low fibre-volume, glass/polyester rectangular plates," Composite structures, vol. 68, pp. 13-22, 2005.

[22] Timoshenko, Stephen P., and Sergius Woinowsky-Krieger."Theory of plates and shells." McGraw-hill, 1959. 
[23] I. K. Giannopoulos, E. E. Theotokoglou, and X. Zhang, "Impact damage and CAI strength of a woven CFRP material with fire retardant properties," Composites Part B: Engineering, vol. 91, pp. 8-17, 2016.

[24] G. Caprino, V. Lopresto, M. Durante, and P. laccarino, "On the first failure energy of glassfiber-reinforced plastic panels impacted at low velocity," Mechanics of Advanced Materials and Structures, vol. 18, pp. 396-402, 2011.

[25] R. M. Boumbimba, C. Froustey, P. Viot, and P. Gerard, "Low velocity impact response and damage of laminate composite glass fibre/epoxy based tri-block copolymer," Composites Part B: Engineering, vol. 76, pp. 332-342, 2015.

[26] Ferdous W, Ngo TD, Nguyen KTQ, Ghazlan A, Mendis P, Manalo A. "Effect of fire-retardant ceram powder on the properties of phenolic-based GFRP composites". Composites Part B: Engineering 201815 December 2018; 155:414-424.

[27] Liang JZ, Feng JQ, Tsui CP, Tang CY, Liu DF, Zhang SD, et al. "Mechanical properties and flame-retardant of PP/MRP/Mg(OH)2/Al(OH)3 composites". Composites Part B: Engineering 201515 March 2015; 71:74-81.

[28] Chen X, Yuan L, Zhang Z, Wang H, Liang G, Gu A. “New glass fiber/bismaleimide composites with significantly improved flame retardancy, higher mechanical strength and lower dielectric loss". Composites Part B: Engineering 201515 March 2015; 71:96-102. 